DOI 10. 18307/2017. 0520

(C) 2017 by Journal of Lake Sciences

\title{
三峡水库运行后长江中游洪、枯水位变化特征”
}

\author{
韩剑桥 $^{1,2}$, 孙昭华 $^{2 * *}$, 杨云平 $^{3}$ \\ ( 1 : 西北农林科技大学, 杨凌 712100) \\ (2: 武汉大学水资源与水电工程国家重点实验室,武汉 430072) \\ (3: 交通运输部天津水运工程科学研究院, 天津 300456$)$
}

\begin{abstract}
摘 要: 流域大型水库蓄水后, 坝下游河道调整过程中的洪、枯水位变化, 对下游水安全、水生态和水资源利用影响甚大. 利用 1955-2012 年长江中游各水文站水位、流量等资料, 采用改进的时间序列分析方法, 对三峡水库运行前后长江中游 洪、枯水位变化特征进行了研究, 结果表明: 三峡水库蓄水前长江中游洪、枯水位变化的周期长度分别为 9 14、11 15 a, 在假设三峡水库运行后水位无趋势性变化的前提下,估算得到的水位变化周期长度基本在 $20 \mathrm{a}$ 以上,蓄水前的自然周期 性已被打破, 枯水位发生趋势性下降且无复归迹象, 而洪水位波动周期虽有所延长, 但上升幅度未超过历史波动变幅, 仅 可确定洪水位没有明显的下降趋势. 三峡水库蓄水后坝下游长距离冲刷, 枯水河槽冲刷量占平滩河槽的比例逐年增加, 累计至 2013 年已达 $91.5 \%$, 是枯水位下降的主控因素. 河槽冲刷导致的床沙粗化增加了河道床面阻力, 高程在平滩水位 附近的滩体上覆盖的大量植被增加了水流流动阻力, 同时大量航道整治、护岸、码头等工程主体部分布设在枯水位以上, 综合因素作用使得洪水河槽阻力增加. 三峡水库蓄水后, 虽然枯水期流量补偿作用显著削弱了枯水位下降的效应, 但枯 水位下降事实已经形成, 不利于航道水深的提高及通江湖泊枯水期的水量存蓄, 洪水位未明显下降, 同级流量下的江湖 槽蓄量不会明显调整.
\end{abstract}

关键词: 三峡水库;水位变化;时间序列分析方法;防洪效益; 长江中游

\section{Flood and low stage adjustment in the middle Yangtze River after impoundment of the Three Gorges Reservoir ( TGR)}

\author{
HAN Jianqiao ${ }^{1,2}$, SUN Zhaohua ${ }^{2 * *} \&$ YANG Yunping ${ }^{3}$ \\ (1: Northwest A \& F University, Yangling 712100, P.R.China) \\ (2: State Key Laboratory of Water Resources and Hydropower Engineering Science, Wuhan University, Wuhan 430072, P.R. \\ China) \\ (3: Tianjin Research Institute of Water Transport Engineering, Tianjin 300456, P.R.China)
}

Abstract: The flood and low stage adjustments in downstream reach of reservoir projects have an important effect on water security,
water ecology and water resource utilization. The variation features of the water stages are studied in the middle Yangtze River after
impoundment of the TGR, based on the hydrological data via one improved method of the time series analysis. The results and con-
clusions are as follows: The low water stage exhibited a decreasing trend due to its periodic time increased from 9-14 years to more
than 20 years, while the flood stage had no decreasing trend because its change amplitude was less than the max value in history.
The main reason for low stage decline is that the erosion amounts in low flow channel increased year by year, when its proportion
accounted for the proportion of bank-full channel even reached at $91.5 \%$ in 2013 . The river resistance has led to flood stage rising
which increased by sand coarsening, vegetation coverage in beach above bank-full stage, and other projects such as navigation reg-
ulation, revetment, and wharf etc. Change in the water stages is harmful to the improvement of channel depth and the water storage
in the reservoir, although the flow discharge compensation of reservoir improves the low flow stage. The water-storage capacities of

* 国家自然科学基金项目(51579185,51339001)、西北农林科技大学博士科研启动基金项目(2452015337)和国家重 点研发计划项目 (2016YFC0402303,2016YFC0402106) 联合资助. 2016-11-06 收稿; 2016-12-28 收修改稿. 韩 剑桥(1987 ), 男, 博士, 助理研究员; E-mail : hjq13@163.com.

** 通信作者; E-mail: Lnszh@126.com. 
lakes have no change because the flood stage is not significantly decreased.

Keywords: Three Gorges Reservoir; stage adjustment; times series analysis method; flood control benefit; middle Yangtze River

流域大型水库蓄水后, 蓄洪补枯作用改变了水库下游的流量过程, 在清水下泄导致的冲刷过程叠加作 用下,河道滩槽冲刷不均,洪水位和枯水位可能出现阶段性或趋势性的变化 ${ }^{[1-2]}$. 尼罗河阿斯旺大坝修建后, 坝下游河床平均下切 $0.45 \mathrm{~m}$,水位下降 $0.8 \mathrm{~m}$, 水面比降减小 ${ }^{[3]}$; 科罗拉多河哥伦峡大坝、密苏里河福特佩克 大坝等水坝的下游河道也出现了水位下降, 水流纵比降变缓的现象 ${ }^{[4-5]}$; 中国汉江丹江口水库修建后,下游 黄家港、襄阳水文站流量小于 $5000 \mathrm{~m}^{3} / \mathrm{s}$ 时, 水位下降 $1.5 \sim 1.7 \mathrm{~m}$, 流量大于 $10000 \mathrm{~m}^{3} / \mathrm{s}$ 时, 水位无明显降低 趋势 ${ }^{[6]}$; 美国密苏里河建库后,在枯水位下降超过 $2.5 \mathrm{~m}$ 的同时,坝下游堪萨斯城洪水位抬高近 $1 \mathrm{~m}^{[7]}$. 综 上,水库下游河道枯水位下降, 而洪水位降幅相对较小甚至有所抬升的水位变化特点,在国内外多条河流上 得到了证实. 枯水位下降与河床下切幅度的大小关系, 决定着航道条件的优劣 ${ }^{[8]}$, 也控制着枯水期通江湖泊 出口的侵蚀基准面,洪水位变化则是防洪 ${ }^{[9-10]}$ 、江湖关系调整 ${ }^{[11]}$ 等更为关注的内容, 因此开展水库下游洪、 枯水位变化的研究具有重要意义.

三峡水库是世界上规模最大的水利枢纽, 在其下游的水沙输移、河床调整、床沙粗化等方面, 国内外学 者进行了大量研究. 针对枯水位变化, 三峡水库蓄水前众多研究单位预测成果一致认为长江中游枯水位将 大幅下降, 水库蓄水后, 航道治理研究人员考虑水库不同运行阶段对枯水流量的补偿作用, 对枯水位与航道 水深的关系开展了大量研究 ${ }^{[12-13]}$. 但对于洪水位的变化, 则一直都存在争议, 部分研究 ${ }^{[14-15]}$ 认为洪水位将会 下降, 由此增加的防洪效益巨大, 另外一部分研究 ${ }^{[16]}$ 则认为洪水位变幅不大, 防洪效益有限. 三峡水库蓄水 后原型观测资料显示, 虽然各站最低水位明显升高, 但长江中游同流量下枯水位下降比较明显, 与预测结果 基本一致 ${ }^{[17]}$, 最高水位有所降低,但同流量下洪水位并未明显下降. 三峡水库运行后坝下游的同流量下洪 水位是否存在下降趋势, 即使结合蓄水后观测资料也难以做出判断, 其主要原因有两个: 一方面是由于年内 水位流量关系的不恒定性, 即使采用校正因素法、落差指数拟合法等单值化处理方法也难以形成稳定的水 位流量关系曲线,并且以此为据生成的水位时间序列难以具有统一的误差标准 ${ }^{[18]}$; 另一方面,年际之间水位 波动性强, 同流量下水位在大水年抬升、小水年回落等非工程因素影响下的波动特性在天然情况下也普遍 存在 ${ }^{[19-20]}$, 三峡水库蓄水后的短期时间内, 水位变化是趋势性调整, 还是正常的周期性波动, 很难在水位时 间序列中加以识别.

鉴于以上问题, 本文利用长江中游各水文站 1955-2012 年水位、流量等资料, 采用改进的时间序列分析 方法以分离提取水位变化的周期性、趋势性、随机性特征, 由此判断水位是否发生趋势性调整; 结合河床形 态、床面阻力、水流阻力及重点人类活动等要素, 分析长江中游洪、枯水位变化的成因, 并探讨水位变化对通 江湖泊出流、航道条件等的影响.

\section{1 研究区域}

长江中游自宜昌至湖口约 $955 \mathrm{~km}$, 其中宜昌至枝城河段长 $61 \mathrm{~km}$, 是山区河流向平原河流的过渡河段, 河床为卵石夹砂组成; 枝城至城陵矶河段习称荆江, 南岸自上而下分别有松滋、太平、藕池 “三口” 分流人洞 庭湖,集纳湘、资、沅、醴“四水” 的洞庭湖出流在城陵矶附近汇人长江干流 ${ }^{[17]}$. 城陵矶至湖口河段河床组成 为细砂及极细砂,其间有汉江、鄱阳湖水系分别在汉口、湖口人汇 (图 1).

长江中游一直是水利、航道部门治理、开发的重点河段, 自 1950s 以来, 以稳定河道、开发河流资源为目 的, 修建了众多水库, 实施了堤防加固、护岸工程、航道整治、岸线利用等工程. 大型人类活动有: 1968-1972 年下荆江实施的系统裁弯工程, 主要对中洲子、上车湾河段进行了人工裁弯, 沙滩子河段发生自然裁弯; 1981 年建成的葛洲坝水利枢纽工程, 导致坝下游河道发生冲刷 ${ }^{[6]} ; 2003$ 年 6 月三峡水利枢纽蓄水运用, 在 蓄水初期坝前蓄水位为 $135 \mathrm{~m}$, 在 2006 年汛末实现了 $156 \mathrm{~m}$ 蓄水, 在 2008 年汛末蓄水水位达到 $172.8 \mathrm{~m}$, 2009 年以后为 $175 \mathrm{~m}$ 正常蓄水位, 水库运行以来削减来沙量达 $80 \%$ 以上 ${ }^{[17]}$. 


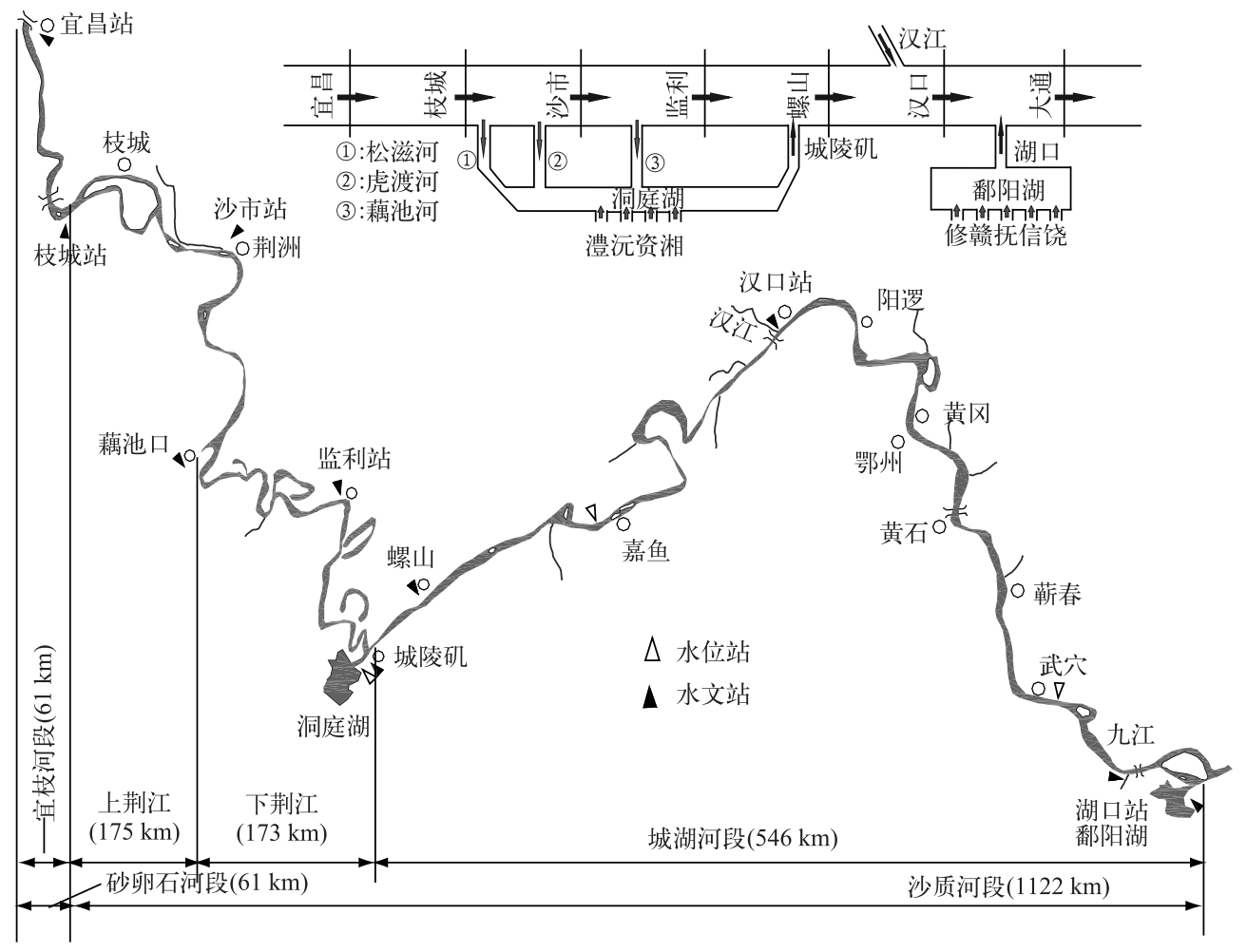

图 1 三峡水库下游河段概略图

Fig.1 The downstream reach of the Three Gorges Reservoir

\section{2 数据来源与研究方法}

\section{1 数据来源}

收集了宜昌、枝城、沙市、螺山、汉口站的水位、流量资料,时段为 1955-2012 年,跨度为 58 a. 其中沙市 站 1991 年建站,之前仅测验水位, 下游 $65 \mathrm{~km}$ 处设有新厂站,两站之间无分汇流,因此 1991 年之前沙市站流 量资料直接引用新厂站实测数据补齐. 监利站受洞庭湖出流随机成分的影响, 水位一流量关系散乱 ${ }^{[17]}$, 本文 暂不涉及其水位变化. 数据来自于长江水利委员会水文局,高程基准均为黄海高程.

\section{2 研究方法}

2.2.1 水位趋势性调整判别指标的选取 对水位趋势性的判别,一般是从水位时间序列中提取趋势成分进行 研究, 但蓄水后周期成分与趋势成分可能相互掺杂, 在 2003 年至今短时间尺度上难以分离. 由于趋势成分 可以看作是周期长度比实测序列长得多的长周期成分, 如存在趋势性变化, 掺杂趋势成分的时间序列周期 时间必然延长 ${ }^{[21]}$, 因此本文采用比较三峡工程影响前后水位变化周期特征的方法, 以此判断蓄水后水位是 否发生趋势性调整. 其具体过程是基于反证法的思路: 首先从水位数据中识别出历史水位波动特征,包括周 期、振幅等; 其次, 假设三峡水库蓄水对长江中游水位无趋势性影响, 即水库蓄水前后长江中游水位一直处 于同种变化状态, 由此得到最近一个周期的变化特征; 最后, 将最近一个变化周期与历史周期的特征值进行 比较,若二者差异巨大, 则说明假设不成立, 即水库蓄水前水位变化的历史规律已被打破. 其判别指标如下:

$$
\begin{cases}S_{\mathrm{P}}>S_{\mathrm{N}} & \text { 水位发生趋势性变化 } \\ S_{\mathrm{P}} \leqslant S_{\mathrm{N}} & \text { 水位未发生趋势性变化 }\end{cases}
$$

式中, $S_{\mathrm{P}}$ 为三峡水库蓄水后的水位周期, $S_{\mathrm{N}}$ 为三峡水库蓄水前的水位周期.

从三峡水库蓄水前、后水位周期波动特性的差别来考察水位变化特点, 需首先生成水位时间序列、消除 
水位时间序列中重要人类活动引起的趋势成分,进而滤除随机成分, 提取周期性特征进行对比分析.

2.2.2 水位时间序列的生成方法 选取连续的 3 日水位和流量数据取平均值, 以消除水流涨落、测量等水位 流量关系不恒定引起的随机误差. 针对水位一流量关系误差在时间序列上的不一致问题, 将多年水位一流量 关系做二次多项式回归曲线, 以同一特征流量下, 特定年份水位相对多年平均回归曲线的残差平均值形成 水文残差时间序列来反映水位的时间变化特点, 残差平均值计算依据公式 (2), 水位残差时间序列可描述为 公式(3) ${ }^{[22]}$ :

$$
\begin{gathered}
e_{i}=y_{i}-\hat{y}_{i} \\
\bar{e}_{n}=\sum_{j=1}^{M} e_{j} / M(n=1,2 、 \cdots, N)
\end{gathered}
$$

式中, $e_{i} 、 y_{i} 、 \hat{y}_{i}$ 分别为每组水位、流量数据的残差、实测值和回归曲线预测值; $\bar{e}_{n} 、 e_{j}$ 分别为特定年份 $n$ 的 残差平均值与该年份中第 $j$ 组水位流量数据残差; $M$ 为年份 $n$ 内的实测点个数; $N$ 为时间序列长度.

考虑到特定特征流量所对应的水位、流量数据点相对较少, 因此将确定水位的特征流量扩展为以特征 流量为中心, 特征流量 $\pm 5 \%$ 范围的流量区间, $5 \%$ 的数值为随机选取. 对于少数在特征流量区间内无流量数 据的年份, 水位残差依据前后年份数据线性插值取得. 特征流量的选取既要反映出洪、枯水位特性, 又要保 证较长时期的一致性,结合实测资料分析,宜昌、枝城、沙市、螺山、汉口水文站的枯水特征流量分别取 6000 、 $6000 、 6000 、 7500$ 和 $12000 \mathrm{~m}^{3} / \mathrm{s}$, 接近多年平均流量的一半, 水流未充满河槽, 洪水特征流量分别取 40000 、 $40000 、 35000 、 40000$ 和 $40000 \mathrm{~m}^{3} / \mathrm{s}$, 水流淹没河漫滩, 可反映出洪水特性.

2.2.3 基于人类活动的水位残差时间序列趋势性成分消除方法 研究河段内曾发生过多次影响重大的人类 活动,所以采用传统水文时间序列趋势线消除趋势性成分的方法并不适用. 本文采用按人类活动年代为分 界分时段取波动中心值计算距平的方法, 将趋势性成分滤除. 其中距平是指原始信号与平均值 (波动中心) 的差值, 更易凸显时间序列中的实际波动特性. 根据工程强度的影响, 以下荆江裁弯、葛洲坝水利工程运用、 三峡水库运用为界分为 4 个时段, 其中葛洲坝水利工程运用后的阶段 3 与阶段 4 统一计算波动中心线数值. 2.2.4 随机成分滤除与周期性特征提取方法 对于水位时间序列中随机成分的滤除问题, 主要应用小波分析 方法. 基于人类活动的水位残差距平时间序列消除高频成分后的低频成分即为水位残差序列的周期波动成 分. 采用 Mallat 快速算法, 小波函数采用 Daubecheis 4 正交小波, 小波母函数 $\psi(t)$ 时间序列 $f(k \Delta t)(k=1$ 、 $2 、 \cdots 、 N)$ 的离散小波的基本计算公式为:

$$
W_{f}(a, b)=\frac{1}{|a|^{1 / 2}} \Delta t \sum_{k=1}^{N} f(k \Delta t) \bar{\psi}\left(\frac{k \Delta t-b}{a}\right)
$$

式中, $a$ 为尺度因子, 反映小波的周期长度; $b$ 为时间因子, 反映时间上的平移; $\Delta t$ 为取样时间间隔; $\bar{\psi}(t)$ 是 $\psi(t)$ 的复共轭函数; $W_{f}(a, b)$ 称小波 (变换) 系数.

周期性特征以周期长度来衡量. 蓄水前周期长度的统计以两个波峰之间的时距为准, 并将各个周期长 度算术平均值作为平均周期长度, 蓄水后没有完整周期, 且大多数站点水位残差在蓄水后处于单向变化状 态, 因此可将其考虑为 $1 / 2$ 周期, 进而推算整个周期时间, 需要说明的是当前水位波动并未完成 $1 / 2$ 个周期, 以此推算的周期长度只是为了对比蓄水前后的变化,不能用以估算调整达到新平衡点的时间.

\section{3 结果分析}

\section{1 水位残差时间序列}

宜昌、枝城、沙市站的枯水位残差、整体下降特点较为明显, 而洪水位残差在葛洲坝水库蓄水前一直处 于波动状态, 2003 年后未出现明显下降趋势. 螺山站枯水位残差在葛洲坝蓄水前基本为负值,之后有增大特 点, 在 1998 年达到峰值 $(1.27 \mathrm{~m}), 2003$ 年后有所下降, 洪水位残差则一直存在较大的波动, 2003 年前后未出 现明显区别. 汉口站枯水位残差一直存在波动, 洪水位与螺山站较为一致 (图 2). 洪、枯水位在一直波动的 长时间水位残差序列里是否有趋势性变化难以判别.

\section{2 基于人类活动的水位残差距平时间序列}

对人类活动引起的趋势因素进行消除, 得到基于人类活动的水位残差距平时间序列 ( 图 3), 下荆江裁弯 


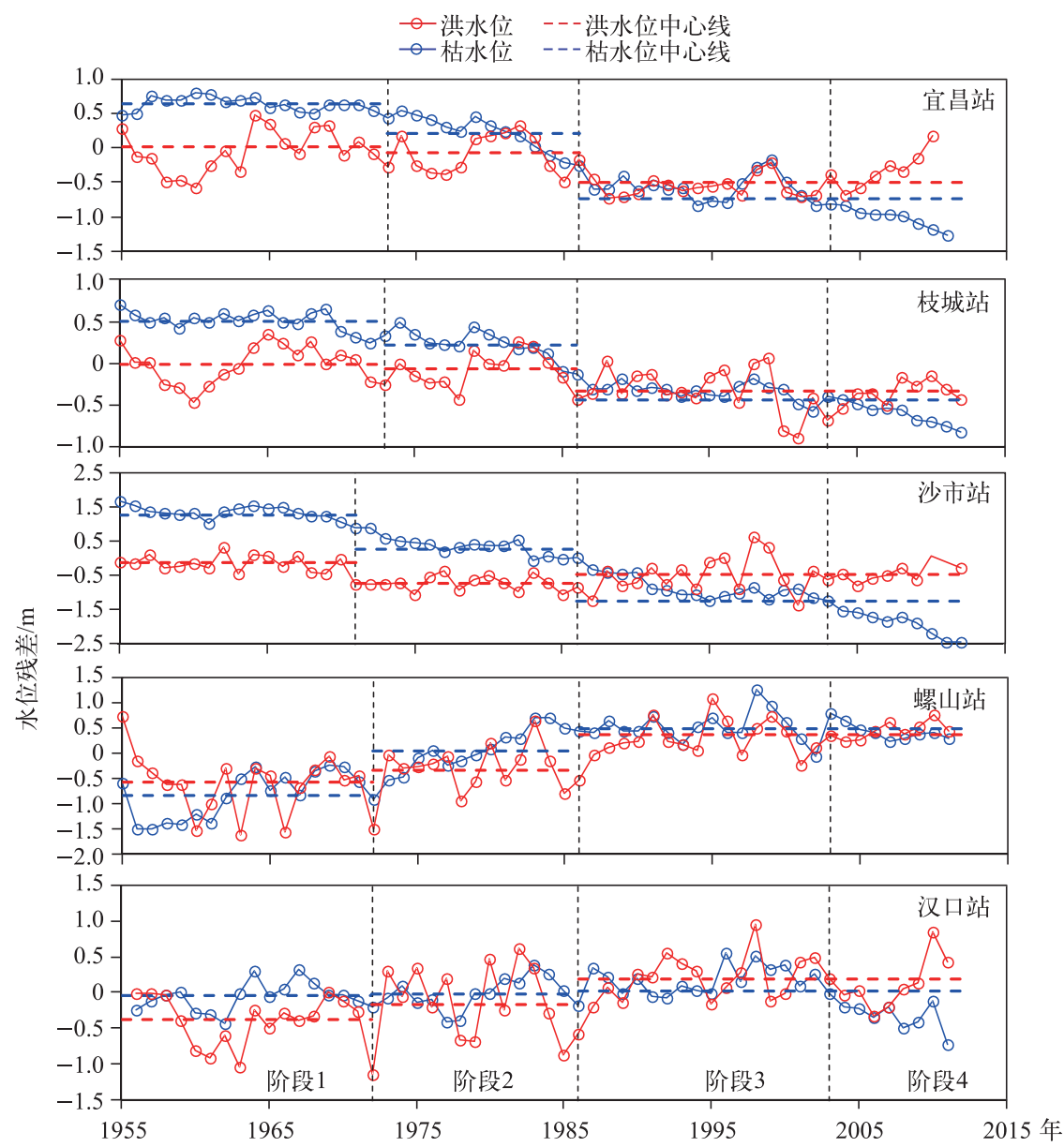

图 2 长江中游各水文站水位残差的时间序列

Fig. 2 Time series of stage residuals at the main gauging stations along the middle Yangtze River

后, 上游宜昌、枝城、沙市水文站枯水位波动中心线分别下降 $0.44 、 0.29$ 和 $1.00 \mathrm{~m}$, 洪水降幅小于枯水降幅; 葛洲坝蓄水后,宜昌水文站枯水位、洪水位波动中心线分别下降 0.94 和 $0.42 \mathrm{~m}$, 沙市水文站枯水位波动中心 线继续下降了 $1.53 \mathrm{~m}$,洪水位由于 1996-1998 年的特高水位而抬高 $0.27 \mathrm{~m}$,这些变化特点与荆江裁弯、葛洲 坝水库蓄水后水位变化的已有研究成果 ${ }^{[23]}$ 在趋势上基本一致. 在去除人类影响分段求距平值后,水位残差 的波动相比原始序列更加规则,但受随机因素的干扰,波动幅度及周期特征仍然难以提取.

\section{3 随机成分滤除及水位趋势性的调整判别}

采用小波分析方法滤除随机成分, 水位残差序列的波动特性较为清晰, 且不与原始序列失真 (图 4). 统 计三峡水库蓄水前的平均水位周期、最大水位周期及蓄水后的水位变化周期 (图 5),其中枯水位残差蓄水后 处于单向下降阶段,洪水位残差处于单向抬升阶段,因此估算得到的蓄水后水位周期是远远偏小的.

1) 枯水位变化. 宜昌、枝城、沙市水文站在蓄水前基本以 $11 \mathrm{a}$ 左右作周期波动变化, 波峰均在 1964 、 1977、1990、1998 年左右出现, 仅波幅有所差异, 蓄水后水位残差持续降低, 周期均已超过 $20 \mathrm{a}$; 螺山、汉口水 文站蓄水前以 $15 \mathrm{a}$ 左右的周期波动变化, 波峰均出现在 1968、1982、1998 年左右, 蓄水后的 2003-2012 年, 水位单向下降, 因此各站周期均大于 $20 \mathrm{a}$, 超过蓄水前的最大周期. 从残差变幅来看, 除了枝城、螺山两站, 其他站点在蓄水后的变幅均超过了历史最大变幅.

2) 洪水位变化. 宜昌、枝城、沙市水文站蓄水前以 $11 \mathrm{a}$ 左右的周期波动变化, 波峰均在 1967、1979、1989、 


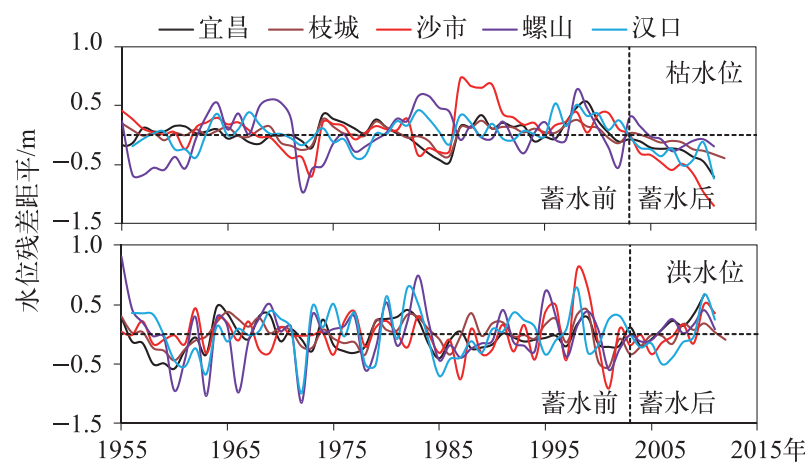

图 3 主要水文站基于人类活动的水位残差距平时间序列

Fig. 3 Time series of stage residuals anomaly according for human activity at the main gauging stations

1998 年附近出现, 蓄水后水位残差均处于相对升高状态, 周期大于 $16 \mathrm{a}$, 超过了蓄水前的周期; 螺山站蓄水 前水位波动的平均周期为 $14 \mathrm{a}$, 蓄水后水位残差处于阶段性增大状态, 波动周期延长为 $20 \mathrm{a}$ 以上; 汉口水文 站洪水位在 2002-2006 年略有下降,而 2006-2012 年持续抬升,因此估算的蓄水后周期在 14 a 以上,大于 蓄水前的周期. 但是需要指出的是, 三峡水库蓄水后, 除宜昌站外, 各站洪水位残差的变幅均未能超过蓄水 前的历史波动最大幅度.

综上,三峡水库蓄水后各水文站特征水位变化的估算周期长度相比自然周期均有所延长, 说明蓄水后 水位残差的时间序列确实存在较多的趋势性成分, 枯水位表现为趋势性下降, 而洪水位由于残差幅度未能 超过历史最大波幅, 仅可判断其没有明显下降趋势, 即洪、枯水位变化存在明显的调整分异规律.

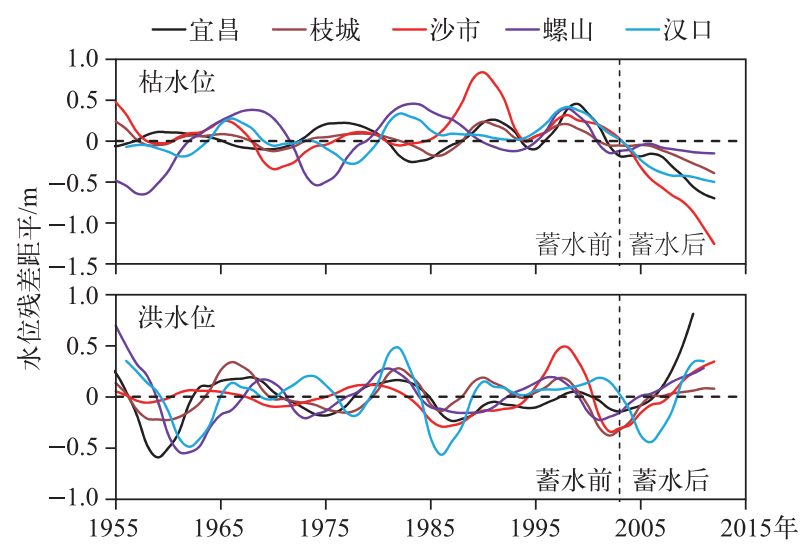

图 4 水位残差的 2 次分解重构系列

Fig.4 Time series of stage residuals with two order decomposition and reconstruction

\section{4 长江中游洪、枯水位调整的成因与意义}

\section{1 三峡水库蓄水前水位变化因素分析}

长江中游水位受来流过程与河道冲淤的直接影响, 上游来流涨落率、下游干支流水流遭遇或流域极端 水沙条件均能引起水位随机性变动, 水沙过程、人类工程引起的河道适应性调整、河床阻力变化等河床边界 条件改变,是同流量下水位调整的主要因素 ${ }^{[6,24-25]}$.

天然来水来沙条件下, 长江干流年际间冲淤交替等现象被已有研究成果所证实 ${ }^{[26]}$, 宜昌至大通河段泥 沙冲淤存在 7 $8 \mathrm{a}$ 的高一低回旋变化, 由此引起河道形态、河床阻力、河床组成等水流边界的复归性调整, 水 
一蓄水前平均 口蓄水前最大 口蓄水后估算
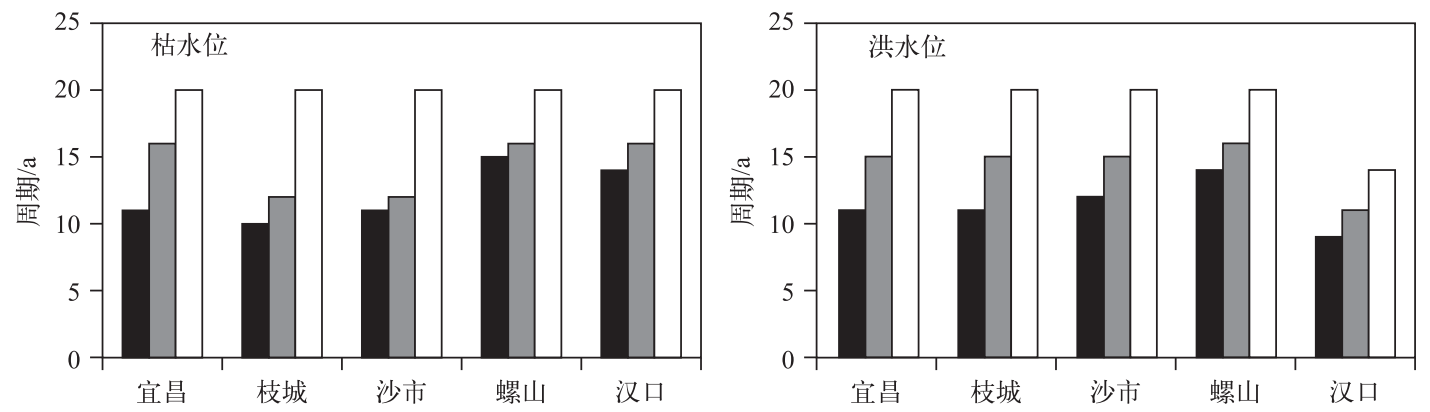

图 5 三峡水库蓄水前后水位变化周期对比

Fig.5 Periodic time variation of water stage before and after the impoundment of the Three Gorges Reservoir

沙过程的波动特性就决定了水位时间序列围绕某一中心线波动的周期特征 ${ }^{[21]}$.

对于人类活动的影响,在三峡水库蓄水前主要考虑荆江裁弯工程、葛洲坝工程. 荆江裁弯工程主要通过 改变下荆江的河道边界, 降低侵蚀基准面导致荆江发生溯源冲刷; 采用地形法计算 1966-1980 年荆江河段 共冲刷 $7.146 \times 10^{8} \mathrm{~m}^{3}$, 不同流量下水位均有所降低, 且洪水降幅小于枯水; 荆江冲刷的泥沙在城陵矶一汉口 河段落淤, 造成了洪水位的抬高, 至 1978 年才基本稳定. 葛洲坝工程拦截了大量推移质泥沙, 导致其下游河 道沿程冲刷, 宜昌水文站至 1991 年, 当流量为 $4000 \mathrm{~m}^{3} / \mathrm{s}$ 时, 水位较建库前降低约 $1.10 \mathrm{~m}$; 当流量为 $20000 \mathrm{~m}^{3} / \mathrm{s}$ 时, 水位降低约 $1.00 \mathrm{~m}$, 坝下游水位至 1991 年左右重新处于相对稳定状态. 这说明人类活动影响下, 河流系 统经过自调整后能达到新的相对平衡状态,适应于新的水沙条件 ${ }^{[27-28]}$.

以上各种因素影响下的水位变化说明, 水文测验获得的水位时间序列, 实际上是河道系统在流域来水 来沙因素作用下的输出信号, 其具有周期成分、随机成分、趋势成分等信号组成特征. 本文的分析表明,长江 中游各站洪、枯水位在三峡水库蓄水前的波动周期为 $11 \mathrm{a}$ 左右,与已有成果 ${ }^{[21]}$ 基本相符,说明本文采用的 研究方法是合理的.

\section{2 三峡水库运行对洪、枯水位的影响}

4.2.1 坝下游河道形态变化的影响 三峡水库蓄水以来, 长江中游河床大幅冲刷, 且多集中于枯水河槽, 20032013 年期间宜昌至湖口河段平滩河槽冲刷 $11.9 \times 10^{8} \mathrm{~m}^{3}$, 枯水河槽占 $91.5 \%$ (图 6). 在河道断面上也可以看 出, 断面扩大范围主要集中于枯水位以下, 枯水位以上变化不大 (图 7), 河床冲刷引起枯水过水面积增大的 比例大于洪水,即河床变形对于枯水的下降影响作用也远大于洪水.

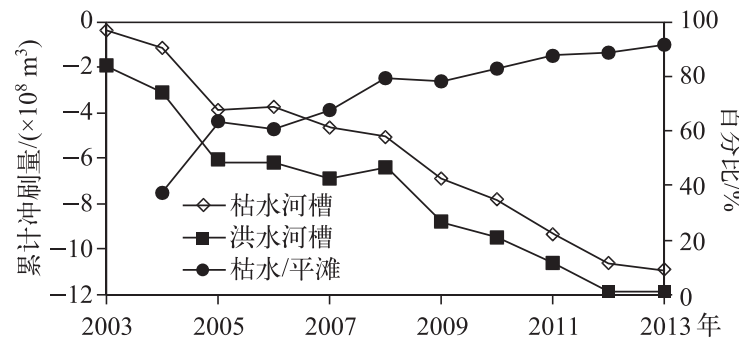

图 6 长江中游河槽冲淤量变化

Fig.6 The channel erosion amount in the middle Yangtze River

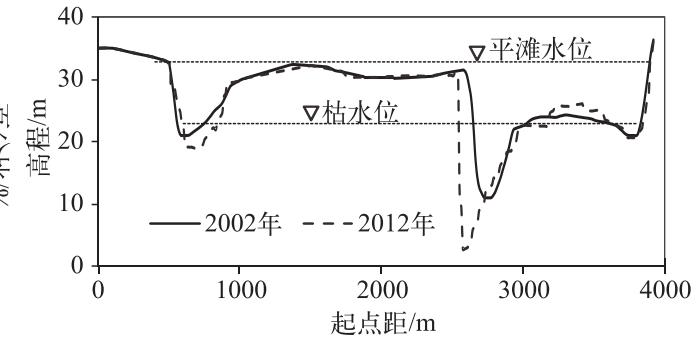

图 7 荆江河段典型断面变化(乌龟洲)

Fig.7 Changes of cross section profile in the middle of Wuguizhou low bench

4.2.2 坝下游河道阻力调整的影响 引起坝下游河道阻力调整的因素主要有床沙粗化、洲滩植被覆盖、整治 工程修建等,下面从这几个方面分别进行阐述： 
1) 河床粗化引起的床面阻力变化. 三峡水库蓄水后, 在坝下游河道冲刷的同时, 河床表层床沙也表现为 粗化趋势 ${ }^{[29-30]}$. 宜昌至枝城河段床沙平均中值粒径由 2003 年 11 月的 $0.638 \mathrm{~mm}$ 增大到 2010 年 10 月的 30.4 $\mathrm{mm}$, 增幅达 48 倍; 枝城至杨家垴河段的床沙中值粒径相比蓄水前增大 20 倍左右. 依照长江科学院提出的䊅 率估算公式进行计算 ${ }^{[31]}$, 引起河床粘率增大 1.65 倍左右, 而荆江沙质河段的精率增大 1.03 倍左右, 城陵矶 一湖口河段的粮率增大 $1.01 \sim 1.03$ 倍, 与沙质河床粒径粗化程度不大相对应.

2) 滩地植被覆盖对水流行进的阻滞作用. 长江中下游为冲积型河流特性, 发育有大量的江心洲和河漫 滩,在三峡水库蓄水后大流量被削减,水流漫滩时间明显减少,洲滩表面长期裸露使得以往高水位淹没的滩 体被植被覆盖. 如长江中游的天兴洲滩体, 高程在平滩水位附近的滩体上生长大量植物, 当洪水漫滩时, 阻 滞了水流行进 ${ }^{[32]}$.

3) 河道与航道治理工程对边界阻力的影响. 2003 年以来, 长江中游实施了大量的航道整治工程, 沙卵石 河段主要是采取护底工程, 直接增加了河床阻力; 沙质河段对边滩和心滩进行守护, 在江心洲头实施守护和 调整型工程. 这些工程主要作用在枯水河槽以上, 一定程度上增大了河道阻力. 水利部门也实施了大量的岸 线加固与守护工程, 在提高长江堤防岸线防洪能力的同时, 也增加了水流的岸壁阻力. 中游河段分布有大量 的码头、景观等工程, 对河道洪水位形成叠加影响, 是增加边界阻力的因素之一 ${ }^{[33]}$.

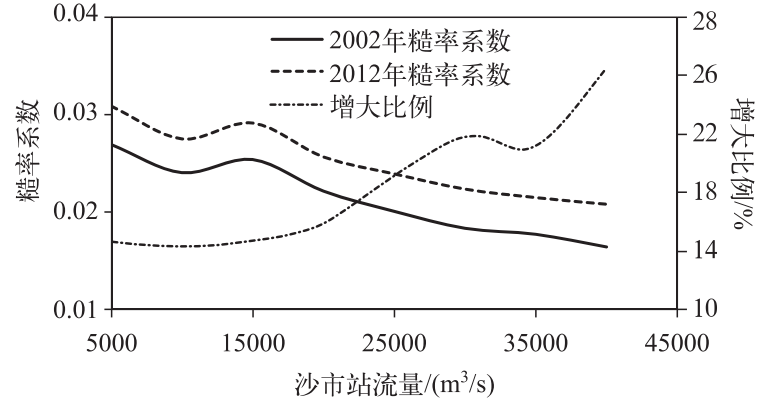

图 8 不同流量下荆江沙质河段粘率系数变化

Fig. 8 Roughness coefficient variation of Jingjiang reach at different discharges

4) 河道综合阻力变化. 根据 2002 和 2012 年实测水面线,采用曼宁公式反算了荆江沙质 河段的粘率系数. 由图 8 可知,各流量下的糙率 系数均呈增大趋势, 说明蓄水后的河床综合阻 力有所增大, 以糙率系数增大值/绝对值作为增 大比例, 可见糙率系数增大比例随流量增大而 增大, 流量小于 $20000 \mathrm{~m}^{3} / \mathrm{s}$ 时, 增大比例在 $14.9 \%$ 左右, 流量大于 $30000 \mathrm{~m}^{3} / \mathrm{s}$ 时, 增大比例 超过了 $20.0 \%$, 最大可达 $26.6 \%$, 说明中枯水流 量下的河床阻力增大值小于洪水流量级. 因此, 蓄水后河道综合阻力增大, 且枯水时期阻力增 大幅度小于洪水时期.

综上,在枯水流量下,河床阻力增大对于水 位抬升效应难以抵消河床下切造成的下降效应, 使得枯水位趋势性降低; 在洪水流量下, 河床阻力增大效应 与河道主槽冲刷效应接近, 使得洪水位并未明显下降.

\section{3 水位变化对通江湖泊、航道条件的影响}

三峡水库蓄水后长江中游河道枯水位趋势性下降, 但最低水位均存在抬升趋势, 如枝城水文站、螺山站 最低水位升高 $1 \mathrm{~m}$ 左右 (图 5), 这显然是由于三峡水库的枯水期补水作用大于同流量水位降幅所致. 2008 年以来, 宜昌站下泄流量均大于 $5000 \mathrm{~m}^{3} / \mathrm{s}$, 相比于蓄水前 $3300 \mathrm{~m}^{3} / \mathrm{s}$ 的最枯流量平均值增加了近 $2000 \mathrm{~m}^{3} / \mathrm{s}$, 但在汛后三峡水库蓄水的 9-11 月份, 宜昌来流被削减, 同流量下水位下降会降低湖泊底水位. 而洪水位未 明显下降,说明同流量下干流河道槽蓄量和通江湖泊调蓄湖容并不会明显增大.

\section{5 结论}

1) 三峡水库蓄水前, 长江中游各水文站同流量下水位波动周期长度在 $9 \sim 15 \mathrm{a}$ 之间, 而在假设三峡水库 运行后长江中游水位无趋势性变化的前提下,估算的各站水位变化周期基本都超过 $20 \mathrm{a}$; 枯水位单向下降, 多站变幅超过历史最大波幅, 存在明显下降趋势, 洪水位阶段性单向抬升, 但变幅未超过历史最大波幅, 仅 可判断其未明显趋势性下降,即存在在洪、枯水位变化不一致的调整分异规律.

2) 河床冲刷与河床阻力增大的综合作用, 是造成洪、枯水位调整分异规律的主要原因. 不同流量下河槽 变形幅度不一致, 泥沙冲刷集中于枯水位河槽; 而床沙粗化、洲滩为植被覆盖、人类涉水工程等引起河床阻 力普遍增大, 在洪水河槽体现更为明显. 
3) 在三峡水库的滞洪补枯作用下,枯水位下降不致对长江中游的航道、取水等问题产生重大不利影响, 但在汛后蓄水阶段可能会增加两湖的出流量, 洪水位未明显下降, 同流量下江湖槽蓄能力变化有限.

需要指出的是, 文中结果均是在现有资料长度上得到的, 三峡水库蓄水时间尚短, 随着河床进一步冲 刷, 高洪水位变化趋势还需进一步跟踪观测. 此外, 文中对河道阻力方面的成因分析较为宏观, 更为细致的 工作尚有待开展.

\section{6 参考文献}

[ 1 ] Petts GE, Gurnell AM. Dams and geomorphology: Research progress and future directions. Geomorphology, 2005, 71(1/ 2) : 27-47.

[ 2 ] Graf WL. Downstream hydrologic and geomorphic effects of large dams on American rivers. Geomorphology, 2006, 79: 336-360.

[ 3 ] Saad MBA. Nile river morphology changes due to the construction of high Aswan dam in Egypt. Egypt: Ministry of Water Resources and Irrigation Report, 2002: 14.

[ 4 ] Shields JR, Douglas F, Simon A et al. Reservoir effects on downstream river channel migration. Environmental Conservation, 2000, 27(1): 54-66.

[ 5 ] Topping DJ, Schmidt JC, Vierra LE. Computation and analysis of the instantaneous-discharge record for the Colorado River at Lees Ferry, Arizona-May 8, 1921, through September 30, 2000. Us Geological Survey Professional Paper, 2003,24 (4) : 30-33.

[ 6 ] Lu Jinyou. Variation of stage-discharge relationship of downstream of hydro-junction. Hydro-Science and Engineering, 1994, (1) : 109-117. [卢金友. 水利枢纽下游河道水位流量关系的变化. 水利水运工程学报, 1994, (1): 109-117.]

[ 7 ] Pinter N, Heine RA. Hydrodynamic and morphodynamic response to river engineering documented by fixed-discharge analysis, Lower Missouri River, USA. Journal of Hydrology, 2005, 302: 70-91.

[ 8 ] Jemberie AA, Pinter N, Remo JWF. Hydrologic history of the Mississippi and lower Missouri Rivers based upon a refined specific-gauge approach. Hydrological Processes, 2008, 22(22): 4436-4447.

[ 9 ] Bormann H, Pinter N, Elfert S. Hydrological signatures of flood trends on German rivers: Flood frequencies, flood heights and specific stages. Journal of Hydrology, 2011, 404(1/2) : 50-66.

[10] Pinter N, Ickes BS, Wlosinski JH et al. Trends in flood stages: Contrasting results from the Mississippi and Rhine River systems. Journal of Hydrology, 2006, 331(3/4) : 554-566.

[11] Zhou Yongqiang, Li Jingbao, Zhang Yunlin et al. Enhanced lakebed sediment erosion in Dongting Lake induced by the operation of the Three Gorges Reservoir. Journal of Geographical Sciences, 2015, 25(8): 917-929.

[12] Tang Jinwu, You Xingying, Li Yitian et al. Impacts of the operation of Three Gorges reservoir on navigation conditions in middle and lower Yangtze River. Journal of Hydroelectric Engineering, 2014, 33(1) : 102-107. [唐金武, 由星芗, 李义 天等. 三峡水库蓄水对长江中下游航道影响分析. 水力发电学报, 2014, 33(1): 102-107.]

[13] Chen Fei, Fu Zhongmin, Liu Huaihan et al. Analysis of navigation conditions in gravel bed reach at initial impounding stage of Three Gorges reservoir. Journal of Hydroelectric Engineering, 2012, 31(5): 127-132. [陈飞, 付中敏, 刘怀汉 等. 三峡蓄水初期坝下沙卵石河段航道条件分析. 水力发电学报, 2012, 31(5): 127-132.]

[14] Jiang Jiahu, Huang Qun. Study on impacts of the Three Gorges Project on its downstream water level. Journal of Hydraulic Engineering, 1997, (8) : 40-44. [姜加虎, 黄群. 三峡工程对其下游长江水位影响研究. 水利学报, 1997, (8): 40-44. ]

[15] Han Qiwei, He Mingmin. Erosion of river reach downstream Three Gorge Reservoir and its influence on flood prevention. Journal of Hydroelectric Engineering , 1995，(3): 34-46. [韩其为，何明民. 三峡水库修建后下游长江冲刷及其对防 洪的影响. 水力发电学报, 1995, (3): 34-46.]

[16] Zhou Jianjun. Problems in the Mid-Yangtze River after the commencement of the Three Gorges Project (TGP). Science and Technology Review, 2006, 24(5) : 49-54. [ 周建军. 三峡工程建成后长江中游应该关注的问题. 科技导报, 2006, 24 (5) : 49-54.]

[17] Han Jianqiao, Sun Zhaohua, Li Yitian et al. The changes and causes of lower water level in Yichang-Chenglingji reach af- 
ter operation of Three Gorges Project. Engineering Journal of Wuhan University, 2011, 44(6) : 685-690, 695. [ 韩剑桥, 孙昭华, 李义天等. 三峡水库蓄水后宜昌至城陵矶河段枯水位变化及成因. 武汉大学学报:工学版, 2011, 44(6): $685-690,695$.

[18] Sun Xiaobo. Discussion on the stage-discharge relationship influenced by flood. Hydrology, 2001, 21(2):41-44. [孙孝 波. 对受洪水涨落影响的水位流量关系单值化的探讨. 水文, 2001, 21(2) : 41-44.]

[19] Hu Siyi, Shi Yong, Qi Chen et al. Systematic analyses on abnormally high flood stages of middle Yangtze River in 1998. Advances in Water Science, 1999, 10(3) : 242-250. [胡四一, 施勇, 戚晨等. 1998 年长江中游洪水系统反演及高洪 水位形成原因探讨. 水科学进展, 1999, 10(3) : 242-250.]

[20] Li Yitian, Ni Jinren. Influence of Sediment Transport on Water Levels in the Middle Yangtze River. Water International, 2001, 26(2) : 191-196.

[21] Xue Xiaojie, Jiang Xiaohui, Huang Qiang. The application ofWavelet analysis in hydrological sequence trend analysis. Journal of Applied Sciences, 2002, 20(4) : 426-428. [薛小杰, 蒋晓辉, 黄强等. 小波分析在水文序列趋势分析中的 应用. 应用科学学报, $2002,20(4): 426-428$. ]

[22] James LA. Channel incision on the Lower American River, California, from streamflow gage records. Water Resources Research, 1997, 33(3): 485.

[23] Pan Qingshen, Lu Jinyou, Hu Xiangyang. Investigation to river channel evolution in Middle Yangtze River from Yichang to Chenglingji. Journal of Yangtze River Scientific Research Institute, 1997, 14(3): 20-23. [潘庆䑁, 卢金友, 胡向阳. 长 江中游宜昌至城陵矶河段河道演变分析. 长江科学院院报, 1997, 14(3): 20-23.

[24] Tang Jinwu, Li Yitian, Sun Zhaohua et al. Preliminary study on the changes of water level at Chenglingji Station after the impoundment of the Three Gorges Project( TGP). Journal of Basic Science and Engineering, 2010, 18(2) : 273-280. [ 唐 金武, 李义天, 孙昭华等. 三峡蓄水后城陵矶水位变化初步研究. 应用基础与工程科学学报, 2010, 18(2): 273-280.]

[25] Huang Ying, Li Yitian, Han Fei. Influences of the Three Gorges Hydropower Station's daily regulation on water surface slope of downstream reach. Hydro-Science and Engineering, 2004, (3) : 62-66. [黄颖, 李义天, 韩飞. 三峡电站日调节 对下游河道水面比降的影响. 水利水运工程学报,2004, (3) : 62-66.]

[26] Yin Hongfu, Chen Guojin, Li Changan et al. Sediment deposition in the middle reaches of the Yangtze River. Science in China: Series D, 2004, (3) : 195-209. [殷鸿福, 陈国金, 李长安等. 长江中游的泥沙淤积问题. 中国科学: D 辑: 地球科学, 2004, (3): 195-209.]

[27] Brandt SA. Classification of geomorphological effects downstream of dams. Catena, 2000, 40(4) : 375-401.

[28] Petts GE, Gurnell AM. Dams and geomorphology: Research progress and future directions. Geomorphology, 2005, 71: $27-47$.

[29] Luo XX, Yang SL, Zhang J. The impact of the Three Gorges Dam on the downstream distribution and texture of sediments along the middle and lower Yangtze River (Changjiang) and its estuary, and subsequent sediment dispersal in the East China Sea. Geomorphology, 2012, 179: 126-140.

[30] Yang Yunping, Zhang Mingjin, Li Yitian et al. Suspended sediment recovery and bedsand compensation mechanism affected by the Three Gorges Project. Acta Geographica Sinica, 2016, 71(7)：1241-1254. [杨云平, 张明进, 李义天等. 长 江三峡水坝下游河道悬沙恢复和床沙补给机制. 地理学报, 2016, 71(7) : 1241-1254.]

[31] Huang Ying, Li Yitian. Water depth maintenance of navigation pass by means of increasing roughness of channel bed. Journal of Hydraulic Engineering, 2005, 36(2) : 141-146. [黄颖, 李义天. 维持通航建筑物口门水深的护底加精措施研 究. 水利学报, 2005, 36(2): 141-146. ]

[32] Chen Zhengbing, Jiang Chunbo. Effect of floodplain vegetation on river hydrodynamic. Journal of Tsinghua University: Science and Technology, 2012, 52(6) : 804-808. [陈正兵, 江春波. 滩地植被对河道水流影响. 清华大学学报: 自然科 学版, 2012, 52(6): 804-808.]

[33] Zhang Xibing, Lu Jinyou, Lin Qiusheng. Preliminary study on accumulated influence of the bankline use on flood control in the middle and lower reaches of the Yangtze River. Resources \& Environment in the Yangtze Basin, 2011, 20(9) : 11381142. [张细兵, 卢金友, 萄秋生. 长江中下游岸线利用对防洪累积影响初步研究. 长江流域资源与环境, 2011, 20 (9) : 1138-1142.] 